\title{
Casereport:
}

\section{A Rare Fracture of The Mandible}

Sulabha $A N^{1}$, Sameer $A C^{2}$,Warad $N M^{3}$

\section{$\underline{\text { Abstract }}$}

Maxillofacial traumas are common and mandible is most frequently fractured bone in the lower third of face. Here we report a rare horizontal fracture of mandible from right molar to left molar. Fracture was adequately reduced and fixed with two holed miniplates. The possible mechanism of such an unusual fracture is discussed.

$\underline{\text { Key Words: }}$ Horizontal fracture, mandible, reduction

\section{Introduction}

Maxillofacial injuries are common. They occur in a variety of situations: road traffic accidents, interpersonal violence, as a result of criminal activity, fall or during the contact sports ${ }^{1}$. Mandible fractures occur more frequently than any other fractures of the facial skeleton. In urban areas in more recent years particularly, interpersonal violence has accounted for an increasing proportion of the mandible fracture along with zygomatic fractures ${ }^{2}$.

The mandible constitutes the bony structure of the lower third of the face.Mandible is the strongest and most rigid component of the facial skeleton. It is more commonly fractured than any other bone of face, a fact directly related to its prominent and exposed situations ${ }^{2}$. The most common sites of fracture in mandible are angle, subcondylar area, body, symphsis, ramus, coronoid process.

Here we report an isolated case of horizontal fracture of mandible below the mental foramen resembling the osteotomy for genioplasty. Extensive research revealed only two cases of horizontal fracture of symphysis.

\section{Case report}

A 35 year old female reported to department of oral medicine with a complaint of swelling in the lower mandibular region since 8-10 days. History revealed that she was hit by a stone in the interpersonal violence 8-10 days before. She developed pain and swelling for which she consulted local dentist and his prescription revealed her of pain and swelling but not completely.

Extra oral examination revealed mild swelling along entire lower mandibular region extending from angle to angle. On palpation it was tender and soft. Intraoral examination revealed no soft tissue abnormality. Occlusion was normal. Panoramic view showed isolated horizontal undisplaced fracture from right molar to left below the mental foramen on both sides (Fig-1).

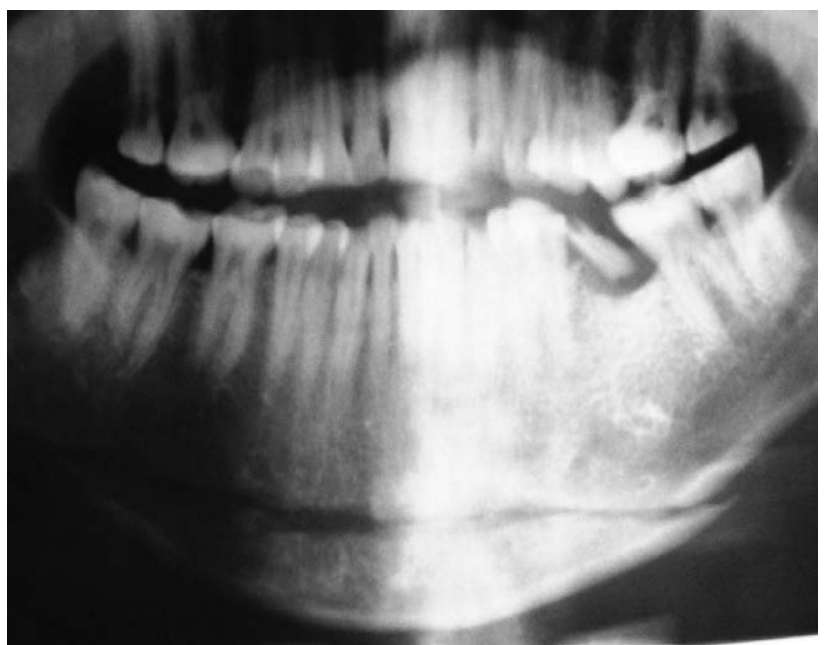

Fig-I Panoramic view of horizontal fracture of mandible

1. Dr. Sulabha .A.N. Professor, Department of Oral Medicine and Radiology, Al-Ameen Dental College and Hospital, Bijapur-586108, Karnataka

2. Dr. Sameer. A.C. Reader, Department of Oral and Maxillofacial Surgery, Al-Ameen Dental College and Hospital, Bijapur-586108, Karnataka

3. Dr. Warad. N.M. Professor, Department of Oral and Maxillofacial Surgery, Al-Ameen Dental College and Hospital, Bijapur-586108, Karnataka

Corresponds to: Dr. Sulabha. A. N. Professor, Department of Oral Medicine and Radiology, Al-Ameen Dental College and Hospital, Bijapur-586108, Karnataka, India,_E-mail: sulabha595@rediffmail.com 


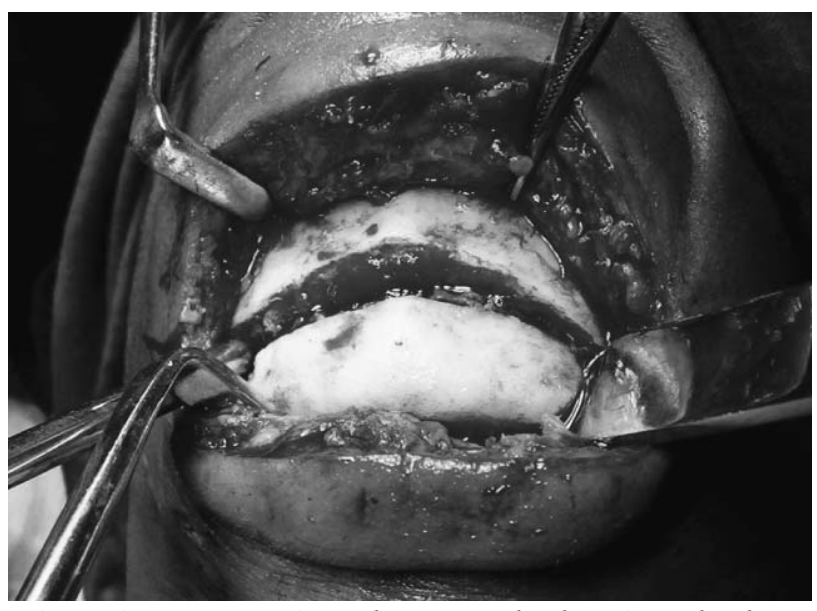

Fig-II intraoperative photograph showing the horizontal fracture

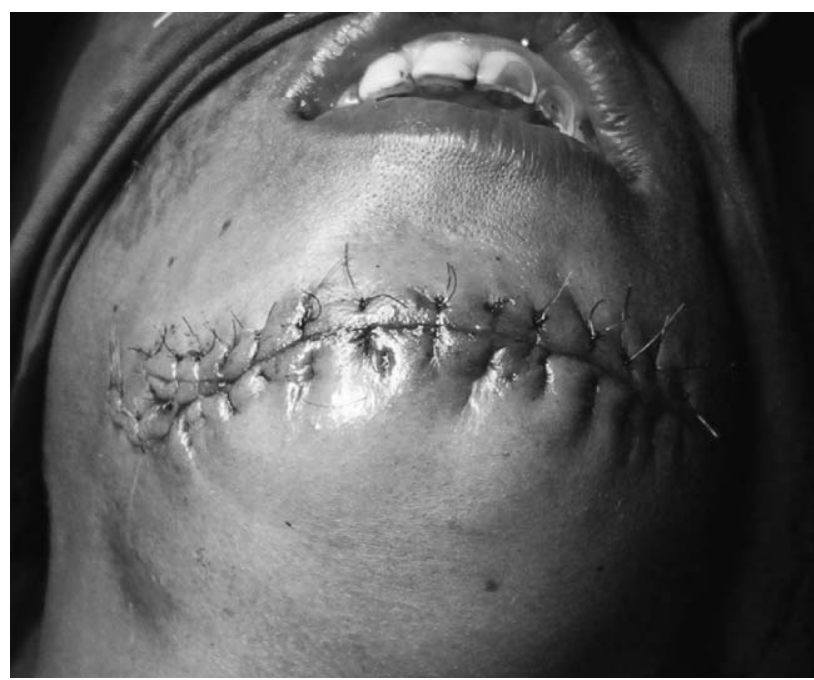

Fig-III Immediate postoperative Photograph

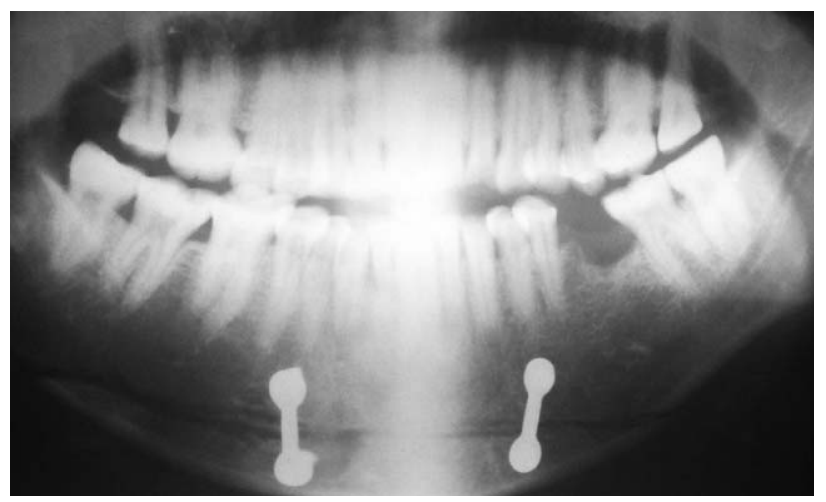

Fig-IV Postoperative radiograph

Risdon's degloving incision was taken from angle to angle, blunt dissection was done to expose the fracture site, and exposed fracture resembled horizontal osteotomy (Fig-II). Fracture site was reduced and two holed two miniplates were fixed on right and left side of mandible at canine region. Incision closure was done in layers (Fig-III). Postoperative healing was uneventful (Fig-IV).

\section{Discussion:}

Despite the many variables associated with the etiology of mandibular fractures, vehicular accidents and assaults are undoubtedly the primary cause of the mandibular fracture throughout the world. Mandibular fracture are more prevalent in the interpersonal violence when compared to accidents which involves majority involves midfacial fractures ${ }^{4}$.

The mandible has few mechanically weak portions including angle, condylar precess and both sides of mentum. The location and direction of mandibular fracture are nearly constant, although the impacts and direction of external force are variable ${ }^{5}$. Mandible having long canines, unerupted third molars, unerupted or absent premolars are significantly weaker and represents the lines of weakness along with the condylar process and both sides of mentum, making these areas more prone for fractures ${ }^{2,6}$.

Isolated horizontal fracture of mandible are rare .Only two cases have been reported in the literature.Ladeinde et al reported horizontal fracture of mandibular symphsis, more involving the left body of mandible caused by matchet cut ${ }^{5}$. Mitsukawa reported a horizontal fracture of mandibular symphysis resembling horizontal osteotomy for genioplasty $^{7}$. In contrast to only reported two cases, the present case involved horizontal fracture from molar to molar.

Lesser violence from interpersonal assaults tends to cause fracture at the usual point of impact on one side $^{2}$. The object that caused the fracture can also influence the type and number of fracture. A blow from smaller well defined object may cause single commutated fracture since the impact of force is concentrated in smaller area ${ }^{3}$.

Horizontal fractures occur only when local stresses exceed the ultimate strength of the bone in that region. Only an object approaching at high speed could produce enough of impact force to fracture the bone in non biomechanical pattern. The object would have to have a horizontal orientation with a sharp edge when striking the mandible and such an acute loading would act like an osteotome to produce the fracture. In the present case high speed 
stone with enough of impact force, having sharp edge might have acted as osteotome to cause such an unusual fracture of mandible ${ }^{5}$.

To conclude such horizontal fractures very rare and occurs when the local stresses exceed the ultimate strength of bone and these fractures need to be classified in classification of mandibular fractures.

\section{References}

1. Booth Pw, Schendel SA, Hausamen JE. Maxillofacial Surgery. Vol 1. Churchill Livingstone, London; 1999: pg 3-11

2. Banks P. Killey's fractures of the mandible. 4th Ed. Varghese publishing house. Bombay.1993: pg 1-19

3. Fonseca RJ, Walker RV, Betts NJ, Barber HD. Oral and Maxillofacial trauma. Vol 1. 2nd Ed.W BSaunders.Phildelphia.1997: pg 473-522

4. Lee KH, Snape L, Steenberg LJ, Worthington J. Comparison between interpersonal violence and motor accidents in the aetiology of maxillomandibular fractures. ANZ J Surg 2007; 77(8):695-98http://dx.doi.org/10.1111/j.14452197.2007.04189.xPMid:17635287
5. Ladeinde AL, Adeyemo WL, Ogunlewe MO, Gbotolorun OM. An unusual fracture of mandible. Ghana Medical Journal 2009; 43 ( 4) : 179 - 80 P M i d : 21326999 PMCid:2956366

6. Reizik M, Lownie JF, Cleaton Jones P, and Austin J. Experimental fractures of monkey mandibles. Int J Oral Surg 1978; 7:100-103 http://dx.doi.org/10.1016/S03009785(78)80054-4

7. Mitsukawa N, Satoh K, Umeura T, Hosaka Y. An unusual traumatic fracture of mandibular symphysis resembling horizontal osteotomy for genioplasty. J Craniofac Surg 2004; 15:229-31 http://dx.doi.org/10.1097/00001665200403000-00011PMid:15167236 